\title{
O DESENVOLVIMENTO DA EDUCAÇÃO AMBIENTAL NA EDUCAÇÃO INFANTIL: IMPORTÂNCIA E POSSIBILIDADES
}

\author{
Leonardo Álisson Pompermayer Verderio ${ }^{1}$
}

Resumo: A presente pesquisa teve por objetivo investigar a importância de desenvolver a Educação Ambiental na Educação Infantil. Para isso, foi realizada uma pesquisa bibliográfica de caráter qualitativo referente a esta temática. Ficou evidenciado que a Educação Ambiental, quando trabalhada desde a Educação Infantil, promove a formação de atitudes e valores na criança em relação ao meio ambiente, promovendo uma postura ecologicamente correta e o desenvolvimento de uma consciência ambiental. $O$ estudo apontou que existem inúmeras possibilidades de promover a Educação Ambiental na Educação Infantil, havendo a necessidade de fornecer uma formação adequada para os professores trabalharem esta temática nas escolas.

Palavras-chave: Educação Ambiental Infantil; Conscientização Ambiental; Prática de Ensino; Educação Básica.

Abstract: This research aimed to investigate the importance of developing Environmental Education in Early Childhood Education. For this, a qualitative bibliographic search was carried out regarding this theme. It was evidenced that Environmental Education when worked since Early Childhood Education promotes the formation of attitudes and values in the child in relation to the environment, promoting an ecologically correct posture and the development of an environmental conscience. The study pointed out that there are numerous possibilities to promote Environmental Education in Early Childhood Education, with the need to provide adequate training for teachers to work on this topic in schools.

Keywords: Child Environmental Education; Environmental Awareness; Teaching Practice; Basic Education.

${ }^{1}$ Universidade Federal de Mato Grosso. E-mail: leonardo verderio@hotmail.com, Link para o Lattes: http://lattes.cnpq.br/6688920815475579

Revbea, São Paulo, v.16, № 1: 130-147, 2021. 


\section{Introdução}

A partir do século XX, mais precisamente nas décadas de 60 e 70, a busca por soluções efetivas para amenizar os problemas ambientais apontou 0 processo educativo como uma possível via para tentar solucionar ou suavizar esses problemas, implicando em um "trabalho de divulgação, conscientização, construção de saberes, revisão de valores e atitudes e de efetiva transformação social, indicando a educação como condição indispensável a isso" (ARNALDO; SANTANA, 2018, p.600).

Desta forma, a Educação Ambiental (EA) surge como um processo educativo que leva a um conhecimento ambiental, concretizando-se nos valores éticos e nas regras políticas de convivência social e de mercado, implicando na questão da distribuição entre os benefícios e os prejuízos relacionados ao apoderamento e uso dos recursos naturais, apresentando-se como um dos instrumentos que pretendem colaborar para a formação de cidadãos críticos em relação à sua realidade (SORRENTINO; TRAJBER; FERRARO JR., 2005). Por isso, a EA torna-se fundamental no processo de formação integral dos indivíduos, pois é através dela que os estudantes começam a ter os primeiros conhecimentos em relação às questões ambientais, passando a ter um novo olhar sobre o meio ambiente, visando à formação de agentes ativos quanto à conservação ambiental, sendo fundamental em todos os níveis de ensino, sobretudo na Educação Infantil (EI) (MEDEIROS, et al., 2011).

Neste sentido, tem-se a El como a primeira etapa da educação básica, objetivando promover a formação integral dos indivíduos. Consequentemente, a EA é tida como parte desse processo e pode contribuir de forma decisiva para essa formação, pois esta, através da interdisciplinaridade, engloba vários fatores relevantes para a formação dos indivíduos, como as emoções, o respeito para com os demais seres vivos, construção do caráter, senso de solidariedade, justiça e pensamento crítico (RODRIGUES; SAHEB, 2018).

Portanto, a elaboração deste artigo se deu através da necessidade de investigar a situação da EA na El, visto que se tem procurado desenvolver cada vez mais uma educação conscientizadora, iniciando este processo desde a primeira etapa da educação básica e considerando-se que quanto mais cedo iniciar o processo de conscientização ambiental do ser humano, mais chances ele terá de tornar-se um cidadão atuante e comprometido com o contexto ambiental.

Diante do exposto, vislumbrou-se uma proposta de estudo que teve como tema "A Educação Ambiental na Educação Infantil". Esta escolha justifica-se por ser principalmente nessa faixa etária que se constroem conceitos e valores para a vida toda, sendo na El que se tem a oportunidade de desenvolver nas crianças valores e condutas voltadas para a conservação do meio ambiente. Além disso, trabalhar com questões que visam refletir sobre estas situações e suas consequências são fundamentais desde a mais tenra idade. Assim, este trabalho teve como objetivo norteador investigar a

revista brasileira educação ambiental 
importância de desenvolver a EA na El, enfatizando também práticas de conscientização ambiental que podem ser desenvolvidas nesta etapa, assim como as limitações da EA nas escolas.

\section{Materiais e métodos}

O presente estudo trata-se de uma pesquisa bibliográfica, de análise qualitativa do conteúdo da literatura pesquisada. Como técnica, a pesquisa bibliográfica compreendeu leitura, seleção, fichamento e arquivo dos tópicos de interesse para discorrer sobre o tema do estudo, com o objetivo de conhecer as contribuições científicas que se efetuaram sobre o assunto: A importância da EA na El.

Para Severino (2007, p. 122) a pesquisa bibliográfica:

[...] é aquela que se realiza a partir do registro disponível, decorrente de pesquisas anteriores, em documentos impressos, como livros, artigos, teses, etc. Utiliza-se de dados ou de categorias teóricas já trabalhados por outros pesquisadores e devidamente registrados. Os textos tornam-se fontes dos temas a serem pesquisados. O pesquisador trabalha a partir das contribuições dos autores dos estudos analíticos constantes dos textos.

Para Gil (2008) a principal vantagem deste tipo de pesquisa é permitir ao investigador a cobertura de uma gama de fenômenos mais amplos. A leitura direcionada dos referidos textos proporcionou o alcance do objetivo proposto neste estudo. Na leitura e análise das publicações, abordou-se a importância da EA na El de forma geral, destacando-se a importância de trabalhar a conscientização ambiental desde a primeira etapa da educação básica; algumas possibilidades de trabalho com a EA na El; e algumas limitações para o ensino da EA nas escolas.

A presente pesquisa deu ênfase à discussão teórica sobre a importância de desenvolver a EA desde a etapa da El, abordando estudos que problematizavam este assunto. A revisão bibliográfica foi desenvolvida com as palavras-chave: Educação Ambiental e educação infantil. Para a obtenção das publicações, foram utilizadas como bases de dados as plataformas Google Scholar e Scielo, livros e revistas eletrônicas. Após criteriosa leitura do material encontrado, optou-se por apresentar um capítulo denominado Educação Ambiental na Educação infantil: Produção teórica, e cinco categorias definidas como: Breve definição da Educação Ambiental; Educação Ambiental: o caminho até as escolas brasileiras; A importância de desenvolver a Educação Ambiental desde a educação Infantil; Possibilidades de inclusão da Educação Ambiental na educação infantil; e, finalmente, Limitações da Educação Ambiental nas escolas. 


\section{Educação Ambiental na Educação Infantil: produção teórica Breve definição da Educação Ambiental}

De acordo com Almeida, Porto e Silva (2020), "a EA pode ser definida por diferentes formas, mas o seu fundamento sempre será o mesmo, desenvolver na sociedade a capacidade de preservar e conservar o meio ambiente". Desse modo, para melhor compreensão do tema a ser abordado nessa pesquisa, aqui serão apresentadas, de forma breve, algumas definições do que vem a ser a EA para posterior discussão acerca de sua importância na El.

De acordo com a Lei n. 9795, de 27/04/1999 que dispõe sobre EA e institui a Política Nacional de Meio Ambiente (PNMA), a EA pode ser compreendida como:

[...] os processos por meio dos quais o indivíduo e a coletividade constroem valores sociais, conhecimentos, habilidades, atitudes e competências voltadas para a conservação do meio ambiente, bem de uso comum do povo, essencial à sadia qualidade de vida e sua sustentabilidade (BRASIL, 1999).

Para Reigota (2014, p. 13) a EA pode ser entendida como [...] "a análise das relações políticas, econômicas, sociais e culturais entre a humanidade e a natureza e as relações entre os seres humanos" [...].

Arnaldo e Santana (2018) compreendem a EA, a partir de um ponto de vista crítico, como uma prática social intencional, possibilitando aos indivíduos condições cognitivas que os permitem, por intermédio de ações coletivas, superar o atual modelo de sociedade, que é marcado pelo capitalismo de dominação e exploração das pessoas entre si e delas com a natureza, objetivando uma mudança estrutural da sociedade e de suas conexões com a natureza. Ainda para os autores, a EA, assim como a própria educação, pode atuar como intermediária de ideias e de ações praticadas na sociedade, destacando conhecimentos e questões que podem contribuir para a prática social voltadas ao meio ambiente e aos problemas socioambientais.

Amaro e Bernardes (2018) acreditam que a EA seja um caminho indispensável para a diminuição dos impactos ambientais, pois apenas 0 conhecimento pode proporcionar mudanças atitudinais nos indivíduos. No entanto, para que isso se concretize, é preciso afastar-se do campo teórico e adotar ações práticas, para que dessa forma consigamos caminhar em favor da preservação ambiental. 


\section{Educação Ambiental: o caminho até as escolas brasileiras}

A EA emergiu frente à preocupação de ecologistas em advertir as pessoas sobre os problemas envolvendo questões ambientais devido à utilização desenfreada de seus recursos naturais, na esperança de que os cidadãos se envolvessem em ações ambientalmente corretas (SOBRAL, 2014; BISSACO; SILVA; REIS, 2016; SILVA; CARNEIRO, 2017).

Há muitos anos, já havia preocupações envolvendo as questões ambientais (ARNALDO; SANTANA, 2018), e a busca por seres humanos ambientalmente conscientes perdura até os dias de hoje. Porém, ainda são muitas as mentes inconscientes e cada vez mais se faz necessária a inclusão da EA nas escolas. Desse modo, por que não iniciar esse processo de construção da consciência ambiental no ambiente escolar ainda na El?

As discussões envolvendo a EA no Brasil, embora tenham surgido tardiamente, começaram muito antes de sua institucionalização por intermédio das políticas públicas (ALBANI; COUSIN; IBAÑEZ, 2019). Neste contexto, de acordo com Arnaldo e Santana $(2018,604)$ :

as políticas públicas de Educação Ambiental se manifestam nas escolas por meio de processos que são permeados por concepções, princípios, objetivos ou, ainda, indicações sobre o modo de realização de trabalho com Educação Ambiental, explicitados nas políticas públicas.

Diante dessa perspectiva, as escolas podem ser vistas como espaços que proporcionam a mediação das políticas públicas de EA (ARNALDO; SANTANA, 2018), estando a EA cada vez mais presente em espaços educacionais, visto que o processo educacional apresenta-se como um grande aliado para a reversão do presente quadro de degradação ambiental em que vivemos (BISSACO; SILVA; REIS, 2016). Neste sentido, foram várias as Leis e marcos históricos que possibilitaram e/ou contribuíram com a inserção da EA nas escolas brasileiras, conforme apresentado no Quadro 1.

Quadro 1: Principais Leis e marcos históricos que contribuíram para o processo de formalização da EA no ensino brasileiro.

\begin{tabular}{|c|l|}
\hline Ano & \multicolumn{1}{|c|}{ Lei/marco histórico } \\
\hline 1972 & $\begin{array}{l}\text { Conferência das Nações Unidas sobre o Meio Ambiente Humano na cidade de } \\
\text { Estocolmo na Suécia. De acordo com Rodrigues (2013), no decorrer da conferência } \\
\text { de Estocolmo, determinou-se que os conteúdos relacionados à EA abordassem } \\
\text { questões educacionais, visando uma sociedade mais organizada e consciente em } \\
\text { relação ao uso de recursos naturais. }\end{array}$ \\
\hline 1973 & $\begin{array}{l}\text { Processo de institucionalização da EA no governo federal brasileiro com a criação } \\
\text { da Secretaria Especial do Meio Ambiente (SEMA) (hoje extinta) vinculada ao } \\
\text { Ministério do Interior (BRASIL, 2014). }\end{array}$ \\
\hline
\end{tabular}

Continua... 
...continuação.

\begin{tabular}{|c|c|}
\hline Ano & Lei/marco histórico \\
\hline 1975 & $\begin{array}{l}\text { A UNESCO realizou em Belgrado, na lugoslávia, uma conferência internacional } \\
\text { sobre a EA, que resultou na criação da Carta de Belgrado, considerada um dos } \\
\text { documentos de maior relevância da década em relação à consciência ambiental } \\
\text { (KLEIN, 2007). }\end{array}$ \\
\hline 1977 & $\begin{array}{l}\text { Conferência Intergovernamental sobre a EA realizada em Tbilisi, na Geórgia } \\
\text { (Conferência de Tbilisi), que foi de extrema importância para o desenvolvimento do } \\
\text { Programa Internacional de Educação Ambiental (PIEA), onde foram traçados } \\
\text { objetivos e estratégias sobre a EA em nível nacional e internacional (SAHEB; } \\
\text { RODRIGUES, 2016). }\end{array}$ \\
\hline 1981 & $\begin{array}{l}\text { i no 6.938/81 dispõe sobre a Política Nacional do Meio Ambiente (PNMA) que } \\
\text { ende em seu Art. } 2^{\circ} \text { inciso X ao seguinte princípio: "Educação Ambiental a todos } \\
\text { s níveis de ensino, inclusive a educação da comunidade, objetivando capacitá-la } \\
\text { ara participação ativa na defesa do meio ambiente" (BRASIL, 1981). }\end{array}$ \\
\hline 1988 & $\begin{array}{l}\text { Constituição Federal de } \\
\text { do Poder Público: "prom } \\
\text { a conscientização públic }\end{array}$ \\
\hline 1991 & $\begin{array}{l}\text { A EA foi cons } \\
\text { Comissão Inte } \\
\text { sobre Meio Am }\end{array}$ \\
\hline 1992 & $\begin{array}{l}\text { Tratado de Educação Ambiental para Sociedades Sustentáveis e Responsabilidade } \\
\text { Global, constitui um importante marco a nível mundial de grande relevância para a } \\
\text { EA; Conferência das Nações Unidas sobre o Meio Ambiente e Desenvolvimento - } \\
\text { Cnumad (Rio-92 ou ECO-92) na qual foi produzida a Carta Brasileira para a } \\
\text { Educação Ambiental, que reconhece a EA como importante instrumento para o } \\
\text { desenvolvimento sustentável e garantia de sobrevivência no planeta Terra (BRASIL, } \\
\text { 2014). }\end{array}$ \\
\hline 1996 & estabelece as diretrizes \\
\hline 1999 & $\begin{array}{l}\text { Lei } n^{\circ} 9.795 / 99 \text { regulamentada pelo Decreto } n^{\circ} 4.281 \text {, de } 25 \text { de junho de 2002, } \\
\text { dispõe sobre a EA, instituiu a Política Nacional de Educação Ambiental (PNEA), } \\
\text { assumindo compromissos internacionais sobre a EA. Esta Lei define em seu artigo } \\
\text { 10ㅇ que: "a Educação Ambiental será desenvolvida como uma prática educativa } \\
\text { integrada, contínua e permanente em todos os níveis e modalidades do ensino } \\
\text { formal" (BRASIL, 1999). }\end{array}$ \\
\hline 2012 & $\begin{array}{l}\text { Aprovação do Parecer CNE/CP } \mathrm{n}-8 / 2012 \text { pelo Conselho Nacional de Educação } \\
\text { (CNE), que estabelece as Diretrizes Nacionais para a Educação em Direitos } \\
\text { Humanos, integrando os direitos ambientais ao documento. Estabeleceu também } \\
\text { que "a educação para a cidadania compreende a dimensão política do cuidado com } \\
\text { o meio ambiente local, regional e global" (OLIVEIRA, et al., 2017); Resolução № } 2 \\
\text { de } 15 \text { de junho de } 2012 \text {, que estabelece as Diretrizes Curriculares Nacionais para a } \\
\text { Educação Ambiental (BRASIL, 2012). }\end{array}$ \\
\hline
\end{tabular}

Fonte: próprio autor.

Nesse contexto, de acordo com Guimarães (2013), o movimento em defesa do meio ambiente começou a ganhar força com os preparativos para a conferência mundial sobre Meio Ambiente e Desenvolvimento (Rio 92), que o 
autor acredita ser o marco inicial em que EA chega de forma institucional ao sistema de ensino formal. Segundo Almeida, Porto e Silva (2020, p.231),

[...] em um contexto nacional, a EA teve o seu processo de desenvolvimento iniciado com a criação da Política Nacional de Meio Ambiente (PNMA), em 1981, através da Lei ํo 6938/81, que dita sobre a necessidade de inclusão da Educação Ambiental em todos os níveis de ensino [...].

A EA, a partir disso, assume um papel muito importante, no sentido de contribuir para a formação da consciência ecológica dos sujeitos, provocando mudanças comportamentais positivas na forma de se relacionar com o meio ambiente (GRZEBIELUKA; KUBIAK; SCHILLER, 2014). Assim, Jacobi (2003, p.196) destaca que:

O desafio é, pois, o de formular uma Educação Ambiental que seja crítica e inovadora, em dois níveis: formal e não formal. Assim a Educação Ambiental deve ser acima de tudo um ato político voltado para a transformação social. $O$ seu enfoque deve buscar uma perspectiva holística de ação, que relaciona o homem, a natureza e o universo, tendo em conta que os recursos naturais se esgotam e que o principal responsável pela sua degradação é o homem.

Visto dessa forma, é importante que a EA seja inserida em todos os

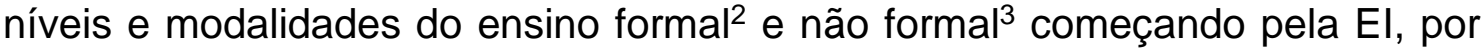
ser a primeira etapa da educação básica e que objetiva o desenvolvimento integral da criança.

No entanto, cabe aqui destacar que o último documento elaborado para nortear o currículo básico das escolas brasileiras, a Base Nacional Comum Curricular (BNCC) (BRASIL, 2017), conforme retratado por Branco, Royer e Branco (2018) em sua pesquisa, não contempla o termo EA na El, assim como em sua primeira versão, que foi alvo de muitas críticas e debates.

2 O ensino formal é aquele trabalhado nas instituições de ensino em todos os níveis e modalidades, mediado pelos professores, ou seja, em sala de aula e dentro dos currículos escolares, e está voltado para o meio ambiente, visando à formação de hábitos e atitudes que preservem os recursos naturais do planeta e, consequentemente, a qualidade de vida das pessoas (HENDGES, 2010).

3 O ensino não formal é aquele que vai além dos muros das escolas e é tratado pela Lei 9.795/99 em seu artigo 13 como "as ações e práticas educativas voltadas à sensibilização da coletividade sobre as questões ambientais e à sua organização e participação na defesa da qualidade do meio ambiente" (BRASIL, 1999). 
Não se diferindo ao proposto nas Referências Curriculares Nacionais para a Educação Infantil (RCNEI) (BRASIL, 1998) e Diretrizes Curriculares Nacionais (DCN) (BRASIL, 2013), a BNCC não contempla o termo EA como componente curricular, apenas sugere que esta seja inclusa ao currículo e às propostas pedagógicas como "temas contemporâneos" de forma "transversal e integradora", envolvendo algumas temáticas como a preservação do meio ambiente, direito da criança e do adolescente, saúde, entre outros (BRANCO; ROYER; BRANCO, 2018). Os autores afirmam ainda que "a EA é citada enquanto determinadas habilidades ou aprendizagens essenciais, porém sem apresentar o termo Educação Ambiental propriamente dito".

\section{A importância de desenvolver a Educação Ambiental desde a educação infantil}

A EA, enquanto proposta pedagógica, direciona-se para a conscientização, mudanças comportamentais, desenvolvimento de competências, habilidade de avaliação e cooperação dos estudantes, além de contribuir para enriquecer o conhecimento e mudanças de valores, condições que visam maior interação e harmonia das pessoas com o meio ambiente (REIGOTA, 1998).

Silva (2012) relata que quando se cultiva o senso de preservação desde os primeiros anos escolares, oportunizando ao indivíduo a possibilidade de desenvolver-se como cidadão consciente de suas atitudes e das consequências que elas trazem para a natureza, contribui para a formação de indivíduos mais conscientes e colaboradores do meio ambiente. Assim, a EA pode também desenvolver outras habilidades e valores que constroem a identidade do cidadão com senso de responsabilidade ambiental.

Desta forma, quando a EA é desenvolvida na El pode gerar mudanças de pensamentos e transformação de valores importantes para promover uma postura ecologicamente correta diante do ambiente em que vivemos, visto que a El é uma fase fundamental para a construção de valores e atitudes da criança perante a sua vida social, ambiental e cultural (ALVES e SAHEB, 2013). E durante o ensino infantil que a criança constrói uma base que orientará sua postura futuramente, sendo mais flexível a mudanças, adoção de novos comportamentos e hábitos pró-ambientais por estar em processo de desenvolvimento. A partir disto, percebe-se a importância de trabalhar os valores sobre o meio ambiente nesta etapa através de práticas reflexivas, contemplativas ou exemplificativas (GRZEBIELUKA; KUBIAK; SCHILLER, 2014; ALVES; SIMEÃO; RAMOS, 2016).

Segundo Oliveira (2012, p. 51), quando a criança é conscientizada, ela observa sua rotina diária e busca fazer alterações em seu comportamento e, por conseguinte, a todos a sua volta, desta forma: "[...] crianças prestam muita atenção a tudo o que veem mesmo quando não intencionamos, procuram 
coerência entre o que falamos e o que realmente fazemos". O autor observa assim a importância da participação dos professores neste processo:

Os professores são fonte inesgotável de modelos e, por isso mesmo, é tão importante explicitar às crianças a intenção que está por trás de cada atitude. Daí que para constituir hábitos de cuidado, de preservação e não desperdício dos recursos naturais, as crianças precisam encontrar no ambiente e nas atitudes dos professores [...], Oliveira (2012, p. 51).

Além disso, através da EA propõe-se a noção de responsabilidade não somente com o mundo e com a sociedade, voltada apenas para uma visão preservacionista, mas também com o próprio sujeito. Segundo Tiriba (2010, p. 2):

Creches e pré-escolas são espaços privilegiados para aprender-ensinar porque lá as crianças colhem suas primeiras sensações, impressões, sentimentos do viver. Sendo assim, a dimensão ambiental não poderia estar ausente, ou a serviço da dimensão cultural, ambas deveriam estar absolutamente acopladas.

Nesse sentido, o desenvolvimento da EA nesta etapa da educação básica, através de atividades que incluam experiências agradáveis e o contato com a natureza, pode fortalecer a construção de valores e atitudes voltados ao respeito e preservação ao meio ambiente. Estudos recentes têm apontado que experiências como essas podem influenciar positivamente crenças e sentimentos em relação à natureza (COLLADO; STAATS; CORRALIZA, 2013; NEIMAN; ADES, 2014; RICHARDSON; SHEFFIELD, 2017).

Crawford, Holder e O'Connor (2017) verificaram em seu estudo que crianças que vivenciaram experiências de lazer em parques abertos tiveram seu sentimento de conexão com a natureza elevada, concordando que a visita as incentivou a cuidar melhor do local. Além disso, a participação constante em atividades de lazer em contato com a natureza esteve associada a uma maior conexão com ela, crenças e comportamento ecologicamente corretos, podendo assim mudar positivamente 0 relacionamento das pessoas com 0 meio ambiente (ROSA; PROFICE, 2018).

Nesse contexto, a EA pode ser abordada de forma interdisciplinar, ou seja, interligada a todos os campos de experiência do currículo escolar. Para tanto é necessário usar a imaginação e metodologias diferenciadas para essa abordagem, sendo o professor nesse caso, uma peça fundamental na mediação do processo de ensino/aprendizagem. Diante disso: 
Em nosso país existe uma enorme carência de conscientização ambiental nos centros educacionais desde as séries iniciais até os cursos de graduação, é necessário incluir disciplinas específicas de Educação Ambiental que sejam trabalhadas de forma interdisciplinar. A inserção da Educação Ambiental como conteúdo curricular é importante e necessária porque é por meio desta que pode desenvolver no indivíduo a consciência ambiental, fazê-lo compreender que a preservação deste meio é preservar o futuro das novas gerações (SILVA; CARNEIRO, 2017, p.199).

Assim, Behrend, Cousin e Galiazzi (2018) acreditam que o universo infantil é bastante produtivo para se desenvolver trabalhos sobre a EA, considerando a diversidade de culturas e interações ali existentes, que são construídas por intermédio das relações das crianças com os adultos e com os demais colegas. De forma complementar, Alves, Simeão e Ramos (2016) enfatizam que professores e escola devem considerar que a criança por estar em processo de desenvolvimento é mais flexível a mudanças, facilitando a formação de cidadãos responsáveis em relação aos cuidados com o meio ambiente numa perspectiva de sustentabilidade ambiental.

Considerando as questões ambientais presentes no cotidiano dos estudantes, é indispensável a busca pela formação e capacitação de indivíduos ambientalmente responsáveis desde cedo. Assim, é importante que professores da El contemplem em seus planejamentos atividades que promovam o conhecimento do meio ambiente e desenvolvimento da consciência ambiental.

\section{Possibilidades de inclusão da Educação Ambiental na educação infantil}

A criança, desde cedo, deve ser estimulada a valorizar e respeitar o meio onde vive, priorizando a coletividade a partir de experiências práticas no dia a dia da sala de aula, buscando dessa maneira o desenvolvimento de hábitos sustentáveis. Reigota (2009, p. 24) afirma que tais experiências podem ser feitas na própria escola, pois ela é um dos lugares privilegiados para a efetivação da EA desde que se dê oportunidade para criatividade.

Ressalta-se ainda que os recursos lúdicos ${ }^{4}$ podem ser uma excelente ferramenta para trabalhar com as questões ambientais na El, pois brincando a criança sente-se mais estimulada, visto que nessa fase ela dá mais importância para a brincadeira do que para atividades formais. A EA deve ser abordada de forma interdisciplinar, tendo como ponto de partida a realidade do aluno, mediando à reflexão, a responderem questionamentos, a despertarem a

\footnotetext{
${ }^{4}$ Recursos lúdicos são aqueles que proporcionam à criança aprender brincando, de uma forma prazerosa e divertida. São de extrema importância na educação infantil.
} 
criticidade e desenvolver a sua conscientização em relação ao seu papel na sociedade.

Schünemann e Rosa (2010) estudaram o desenvolvimento de diferentes atividades através de temáticas ambientais, em que os assuntos eram decididos entre o professor e os alunos, partindo da necessidade e curiosidade dos estudantes. Segundo os autores, eles demonstraram curiosidade, interesse e muita vontade de aprender e ampliar seus conhecimentos, despertando o interesse por temas ambientais, recomendando assim o desenvolvimento da EA desde a El. Neste sentido, Reigota (2014, p. 46), afirma:

$\mathrm{Na}$ Educação Ambiental escolar deve-se enfatizar o estudo do meio ambiente onde vive o aluno e a aluna, procurando levantar os principais problemas cotidianos, as contribuições da ciência, da arte, dos saberes populares, enfim, os conhecimentos necessários e as possibilidades concretas para a solução deles.

Grzebieluka, Kubiak e Schiller (2014) analisaram a aplicação do projeto "Cores, cheiro e sabores: a reestruturação do espaço ocioso" desenvolvido em uma escola de El, como a proposta de desenvolver a EA através da construção e manutenção de uma horta, jardim e uma série de outras atividades, buscando envolver toda a comunidade escolar. O trabalho valorizou a realidade dos alunos, assim como seus conhecimentos prévios, resultando na mudança de atitude dos estudantes em relação à preservação e cuidado com o meio ambiente. De forma complementar, Sprestesojo, Mazari e Girotti (2017) constataram em sua pesquisa, que a maioria dos profissionais entrevistados acredita que o desenvolvimento de projetos de EA através da horta escolar na El contribui para o desenvolvimento da consciência ambiental dos estudantes.

Santos e Silva (2016) exploraram o desenvolvimento da EA na EI através do uso de recursos tecnológicos. Em seu trabalho os autores abordaram diferentes possibilidades de atividades para a promoção da consciência ambiental, dentre elas, o reaproveitamento de materiais recicláveis, o uso de recursos audiovisuais (animações e charges), sites e jogos educativos.

Outra proposta refere-se ao trabalho com a EA através de temas geradores, partindo da realidade local do aluno, conforme Agnol e Aguiar (2018). Neste estudo, os autores desenvolveram primeiramente três encontros formativos para promover a formação continuada dos professores municipais de uma escola municipal de Porto Nacional (TO), e, a partir do interesse de uma professora que participou da formação, desenvolveram uma ação ambiental visando promover a construção do conhecimento, de atitudes e habilidades necessárias para a preservação e melhoria da qualidade ambiental. A ação ambiental consistiu em discussões, práticas de reutilização de materiais recicláveis (lúdico), visitas e socialização do conhecimento construído. Apesar dos autores desenvolverem a proposta com alunos do Ensino Fundamental I, é 
possível realizar a adaptação dos conteúdos para possibilitar o desenvolvimento desta proposta na El.

Ainda na perspectiva de adaptação de situações que promovam o desenvolvimento da consciência ambiental para os alunos da El, Santos e Vasconcelos (2018) desenvolveram atividades de exposições de conteúdos teóricos, saídas de campo, trilhas ecológicas, coleta e reutilização de garrafas PET para a construção de uma estufa sustentável, arborização da escola, entre outras atividades de cunho lúdico a fim de promover a EA com estudantes da segunda etapa da educação básica.

Recentemente, Almeida, Porto e Silva (2020) discutiram em seu estudo a elaboração de histórias em quadrinhos sobre o aquecimento global como material didático alternativo para turmas do Ensino Fundamental II, que pode ser utilizado como prática da EA, inclusive na $\mathrm{El}$, a fim de formar cidadãos conscientes e ativos em relação ao meio ambiente. Outros autores que também obtiveram sucesso em seu estudo foram Cunha e colaboradores (2020), que a partir da utilização de literatura infantil voltada para a EA, obtiveram resultados positivos para a promoção da conscientização ambiental de estudantes da El. Os autores também concluíram que as crianças têm grande capacidade de aprender a partir dos recursos lúdicos voltados para a EA.

Assim, percebe-se que existem inúmeras possibilidades de abordar as questões ambientais no ambiente escolar, sendo importante estabelecer uma parceria entre a escola, família e comunidade, com intuito de que o trabalho realizado na El seja fortalecido.

\section{Limitações da Educação Ambiental nas escolas}

Atualmente, são muitas as dificuldades e as demandas encontradas no campo educacional e que precisam ser superadas, destacando-se uma formação adequada dos professores, (re) definições do papel desempenhado pela escola na sociedade contemporânea e a busca por melhores formas de abordar os problemas ambientais dentro da EA no cenário escolar (BRANCO; ROYER; BRANCO, 2018).

Dentre as principais limitações encontradas pela EA nas escolas, está a formação dos professores para desempenhar este trabalho de conscientização ambiental. Esta problemática é evidenciada no estudo de Saheb e Rodrigues (2016), que apontou que os educadores das instituições avaliadas, assim como seu Projeto Político Pedagógico (PPP) possuem algum conhecimento sobre a EA e reconhecem a importância desta temática para a El. Porém, as informações apresentadas pelos educadores e contidas no PPP da escola são insuficientes para o desdobramento de boas práticas de EA na El. Os educadores que participaram do estudo enfatizaram que existe a necessidade de a EA ser mais trabalhada nos cursos de formação para que haja a ampliação e solidificação de seu espaço nas discussões e práticas na El. 
Alves e Saheb (2013) constataram que o acesso dos docentes a materiais que discutem o tema EA é restrito, recorrendo, quando necessário, a pesquisas na internet e informações fornecidas pela mídia. Ainda neste estudo os autores concluíram que, apesar de existirem tentativas de implantar a EA, ainda existe pouca prática e interdisciplinaridade, sendo limitado o conhecimento dos professores, possivelmente pela carência de programas governamentais de incentivo e capacitação desses profissionais.

Tozoni-Reis e colaboradores (2013) afirmam que é necessário problematizar os processos formativos. De acordo com eles, uma das possibilidades de reflexão-ação para a EA crítica e transformadora na educação escolar é dependente da formação plena, consciente e consequente dos professores da Educação Básica, sendo necessário que esta formação esteja atrelada a produção de conhecimento científico na área de EA, superando a distância entre o mundo acadêmico e a Educação Básica.

Assim, diante do exposto pelos autores quanto à formação dos professores para desenvolverem a conscientização ambiental, ressalta-se a necessidade da EA ser valorizada e passar a constituir a formação dos professores, tanto durante a sua formação acadêmica quanto fazer parte da sua formação continuada.

\section{Considerações finais}

O presente estudo evidenciou a importância de se trabalhar a EA ainda na El. Nesta perspectiva, ao abordar temas ligados a EA com as crianças, estas podem despertar curiosidade pelo assunto e desenvolver seu senso crítico, compreendendo o que é certo e o que é errado em relação ao meio ambiente.

A El é um campo fértil para trabalhar as questões ambientais, uma vez que as crianças são suscetíveis a novos conhecimentos. Porém, o trabalho deve ser desenvolvido de forma continuada, visando à construção de uma sociedade sustentável. Assim, faz-se necessário recriar diversas funções e papéis profissionais, pessoais e institucionais, desenvolvidos na sociedade para garantir um futuro melhor para as próximas gerações.

Para isso, a escola e os professores devem estar preparados para a abordagem de questões ambientais com os estudantes desde a primeira etapa da Educação Básica, sendo a El uma etapa propícia para isso, pois neste período a criança constrói sua concepção de conceitos e atitudes para o futuro. Neste sentido, quando elas se deparam com problemas ambientais provenientes do seu cotidiano ou até mesmo os abordados na mídia, é visível que elas demonstram grande preocupação com tais situações, e a partir dessa comoção podem desenvolver valores relacionados ao meio ambiente.

Embora existam diversas formas de abordagem da EA na EI, conforme apresentadas nesse estudo, ainda é necessário desenvolver mais pesquisas nessa área, bem como a necessidade de promover uma formação adequada 
aos professores para que eles possam trabalhar a EA dos estudantes, para que de fato essa inclusão se consolide dentro das escolas.

Por fim, salienta-se que esse tema deve ser tratado como uma necessidade, pois as crianças de hoje serão os adultos de amanhã, os quais se tiverem uma consciência ecológica crítica poderão ser os atores principais na busca de uma sociedade mais justa e equilibrada em relação às questões ambientais.

\section{Referências}

AGNOL, M. D.; AGUIAR, D. R. C. A práxis pedagógica no ensino da Educação Ambiental crítica em uma escola da rede pública municipal de ensino de Porto Nacional (TO). Revista Brasileira de Educação Ambiental (Revbea), São Paulo, V. 13, n. 4, p. 126-145, dez. 2018.

ALBANI, I. C.; COUSIN, C. S.; IBAÑEZ, M. E. A Educação Ambiental no Brasil e na Espanha: reflexões alicerçadas na perspectiva crítica e transformadora. Rev. Eletrônica do Mestrado em Educação Ambiental, Rio Grande do Sul, v. 36, n. 3, p. 212-234, dez. 2019.

ALMEIDA, B. C.; PORTO, L. J. L. S.; SILVA, C. M. Construção de histórias em quadrinhos como recurso didático para a Educação Ambiental. Revista brasileira de Educação Ambiental (Revbea), São Paulo, v. 15, n. 3, p. 229 245, 2020.

ALVES, A. P.; SAHEB, D. A Educação Ambiental na educação infantil. In: CONGRESSO NACIONAL DE EDUCAÇÃO, 9., 2013. Anais...Curitiba: PUCPR, 2013. Disponível em: $<$ https://educere.bruc.com.br/arquivo/pdf2013/7774 6497.pdf>. Acesso: 22 jul. 2020.

ALVES, D. A.; SIMEÃO, E. M. S.; RAMOS, M. L. Educação Ambiental na educação infantil: como e porque sua abordagem com crianças nessa faixa escolar. Colloquium Humanarum, v. 13, n. Especial, jul./dez, p. 262-267, 2016.

AMARO, F. T.; BERNARDES, M. B. J. Educação Ambiental como instrumento de mitigação de impactos ambientais: experiências com Programas de Educação Ambiental (PEA's) desenvolvidos para linhas de transmissão de energia elétrica. Revista Eletrônica do Mestrado em Educação Ambiental, Rio Grande, v. 35, n. 3, p. 152-169, set./dez. 2018.

ARNALDO, M. A.; SANTANA, L. C. Políticas públicas de Educação Ambiental e processos de mediação em escolas de Ensino Fundamental. Ciência \& Educação, Bauru, v. 24, n. 3, p. 599-619, abr. 2018.

BEHREND, D. M.; COUSIN, C. S.; GALIAZZI, M. C. Base Nacional Comum Curricular: o que se mostra de referência à Educação Ambiental? Ambiente \& Educação, v. 23, n. 2, p. 74-89, 2018. 
BISSACO, C. M.; SILVA, D. M.; REIS, D. A. Educação Infantil, Educação Ambiental e construção de valores: uma proposta de formação docente. Revista Eletrônica do Mestrado em Educação Ambiental, Rio Grande, v.33, n.1, p.233-255, jan./abr. 2016.

BRANCO, E. P., ROYER, M. R.; BRANCO, A. B. G. A abordagem da Educação Ambiental nos PCNs, nas DCNs e na BNCC. Nuances: estudos sobre Educação, Presidente Prudente-SP, v. 29, n. 1, p.185-203, Abr., 2018.

BRASIL, Lei no 6.938/81, de 31 de agosto de 1981. Diário Oficial [da] República Federativa do Brasil, Brasília, 31 de agosto de 1981. Disponível em: <http://www.planalto.gov.br/ccivil 03/LEIS/L6938.htm>. Acesso: 15 jul. 2020.

BRASIL, Constituição da República Federativa do Brasil de 1988. Promulgada em 05 de outubro de 1988. Disponível em: $<$ http://www.planalto.gov.br/ccivil 03/constituicao/constituicao.htm>. Acesso: 23 abr. 2020.

BRASIL, Lei no 9.394, de 20 de dezembro de 1996. Estabelece as diretrizes e bases da educação nacional. Diário Oficial da União, Brasília, DF, 23 dez. 1996. Disponível em: <http://www.planalto.gov.br/ccivil 03/leis/19394.htm>. Acesso em: 26 mar. 2020.

BRASIL, Ministério da Educação. Secretaria de Educação Fundamental. Referencial Curricular Nacional para a Educação Infantil. Brasília: MEC/SEF, $1998 . \quad$ Disponível em: $<$ http://portal.mec.gov.br/seb/arquivos/pdf/volume3.pdf>. Acesso: 20 jul. 2020.

BRASIL, Lei no 9.795, de 27 de abril de 1999. Dispõe sobre a Política Nacional de Educação Ambiental e da outras providências. Diário Oficial, Imprensa nacional: $\quad$ Brasília, $1990 . \quad$ Disponível em: <http://www.planalto.gov.br/ccivil 03/LEIS/L9795.htm>. Acesso: 23 abr. 2020.

BRASIL, Decreto no 4.281, de 25 de junho de 2002. Regulamenta a Lei no 9.795, de 27 de abril de 1999, que institui a Política Nacional de Educação Ambiental, e dá outras providências. Brasília, 2002. Disponível em: $<$ http://www.planalto.gov.br/ccivil 03/decreto/2002/D4281.htm>. Acesso: 20 jul. 2020.

BRASIL, Parecer CNE/CP, no 8/2012. Estabelece as Diretrizes Nacionais para a Educação em Direitos Humanos. Ministério da Educação e Conselho Nacional de Educação, 2012. Disponível em: $<$ http://portal.mec.gov.br/index.php?option=com docman\&view=download\&alia

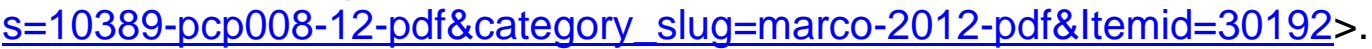
Acesso: 20 jul. 2020.

BRASIL, Resolução CNE/CP 2/2012. Diário Oficial da União, Brasília, 15 de junho de 2012 - Seção 1 - p. 70. Disponível em: <http://portal.mec.gov.br/ index.php?option=com docman\&view=download\&alias=10988-rcp002-12pdf\&category slug=maio-2012-pdf\&ltemid=30192>. Acesso: 15 jul. 2020. 
BRASIL, Ministério da Educação. Diretrizes Curriculares Nacionais da Educação Básica. Brasília: MEC, SEB, DICEI, 2013. Disponível em: $<$ http://portal.mec.gov.br/index.php?option=com docman\&view=download\&alia

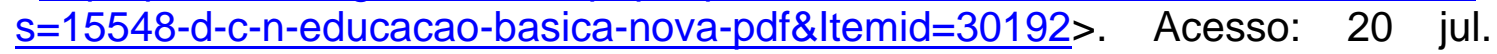
2020.

BRASIL, Programa Nacional de Educação Ambiental - ProNEA: documento básico. Ministério do Meio Ambiente, Diretoria de Educação Ambiental; Ministério da Educação, Coordenação Geral de Educação Ambiental. 4 ed. Brasília, 2014. Disponível em: <https://www.mma.gov.br/publicacoes/educacaoambiental/category/98-pronea.html>. Acesso: 22 jul. 2020.

BRASIL. Ministério da Educação. Base Nacional Comum Curricular. Brasília: MEC, 2017. Disponível em: <http://basenacionalcomum.mec.gov.br/ images/BNCC 20dez site.pdf>. Acesso: 23 mar. 2020.

COLLADO, S.; STAATS, H.; CORRALIZA, J. Experiencing nature in children's summer camps: Affective, cognitive and behavioural consequences. Journal of Environmental Psychology, v. 33, p. 37-44, 2013.

CRAWFORD, M.R.; HOLDER, M.D.; O'CONNOR, B.P. Using Mobile Technology to Engage Children With Nature. Environment and Behavior, v. 49, n. 9, p. 959-984. 2017.

CUNHA, C. R.; NASCIMENTO, C.; DALL'ORTO, J. A. C.; SILVA, J. G. F. A literatura infantil e sua possibilidade de abrir horizontes em relação à Educação Ambiental na primeira infância. Revista brasileira de Educação Ambiental (Revbea), São Paulo, v. 15, n. 1, p. 431-441, 2020.

GIL, A. C. Métodos e técnicas de pesquisa social. 6 ed. São Paulo: Atlas, 2008. 220p.

GRZEBIELUKA, D.; KUBIAK, I.; SCHILLER, A.M. Educação Ambiental: A importância deste debate na Educação Infantil. Revista Monografias Ambientais, v.13, n.5, p.3881-3906, dez. 2014.

GUIMARÃES, M. Por uma Educação Ambiental crítica na sociedade atual. Revista Margens Interdisciplinar, v.7, n.9, p.01-12, 2013.

HENDGES, A. S. Educação Ambiental no Ensino Formal e Não Formal, Lei 9.795/1999. Ecodebate cidadania e meio ambiente, 2010. Disponível em: $<$ https://www.ecodebate.com.br/2010/09/13/educacao-ambiental-no-ensino-

formal-e-nao-formal-lei-9-7951999-artigo-de-antonio-silvio-hendges/>. Acesso: 30 abr. 2020.

JACOBI, P. Educação Ambiental, Cidadania e Sustentabilidade. Cadernos de Pesquisa, n. 118, p. 189-205, mar. 2003.

KLEIN, A. L. Educação Ambiental na Educação Infantil: um estudo de caso na fazenda quinta da estância grande - Viamão/RS. 2007. 78 f. Monografia (Pós Graduação em Educação Ambiental). Universidade Federal de Santa Maria, RS, $2007 . \quad$ Disponível em: $<$ http://jararaca.ufsm.br/websites/unidadedeapoio/download/Angelaklein >.

Acesso: 25 abr. 2020. 
MEDEIROS, A. B.; MENDONÇA, M. J. S. L.; SOUSA, G. L.; OLIVEIRA, I. P. A importância da Educação Ambiental na escola nas séries iniciais. Revista Faculdade Montes Belos, v. 4, n. 1, set. 2011.

NEIMAN, Z.; ADES, C. Contact with nature: effects of field trips on proenvironmental knowledge, intentions and attitudes. Ciência \& Educação, Bauru, v. 20, n. 4, p. 889-902, 2014.

OLIVEIRA, J.; XAVIER, A. R.; ALCÓCER, J. C. A.; XAVIER, L. C. V.; RODRIGUES, R. M. Educação Ambiental e a legislação brasileira: contextos, marco legal e desafios para a educação básica. Educação Ambiental em Ação, n. 59, Ano XV, mar./mai. 2017.

OLIVEIRA, Z. R. O Trabalho do professor na educação infantil. 1. Ed. São Paulo: Biruta, 2012.

REIGOTA, M. Desafios à Educação Ambiental escolar. In: JACOBI, P. et al. (orgs.). Educação, meio ambiente e cidadania: reflexões e experiências. São Paulo: SMA, p. 43-50, 1998.

REIGOTA, M. O que é Educação Ambiental? 2ª ed. São Paulo: Brasiliense, 2009.

REIGOTA, M. O que é Educação Ambiental. (coleção primeiros passos). São Paulo: Brasiliense, 2014. 112p.

RICHARDSON, M.; SHEFFIELD, D. Three good things in nature: noticing nearby nature brings sustained increases in connection with nature, Psyecology, v. 8, n. 1, p. 1-32, 2017.

RODRIGUES, D. G.; SAHEB, D. A Educação Ambiental na educação infantil segundo os saberes de Morin. Revista Brasileira de Estudos Pedagógicos, Brasília, v. 99, n. 253, p. 573-588, set./dez. 2018.

RODRIGUES, S. J. Educacion Ambiental: una propuesta para la educación secundaria. Ambiente e Educação, v. 18, n. 1, p. 113-138, 2013.

ROSA, C. D.; PROFICE, C.C. Que tipo de Educação Ambiental e para quem? Fatores associados a atitudes e comportamentos ambientais. Revista Brasileira de Educação Ambiental (Revbea), São Paulo, v. 13, n. 4, p. 111125, dez. 2018.

SAHEB, D.; RODRIGUES, D. G. A Educação Ambiental na educação infantil: limites e possibilidades. Cadernos de Pesquisa, São Luís, v. 23, n. 1, p. 8194, jan./abr. 2016.

SANTOS E. A. V.; VASCONCELOS, M. T. O. A Educação Ambiental no ensino básico através das intervenções do PIBID e as contribuições do programa para a formação docente. Revista Brasileira de Educação Ambiental (Revbea), São Paulo, V. 13, n. 4, p. 51-65, dez. 2018.

SANTOS, C. F.; SILVA, A. J. A importância da Educação Ambiental no ensino Infantil com a utilização de recursos tecnológicos. Revista Gestão \& Sustentabilidade Ambiental, v.5, n.2, p.4-19, out.2016/mar. 2017. 
SCHÜNEMANN, D. R.; ROSA, M. B. Conscientização ambiental na educação infantil. Revista Monografias Ambientais, v. 1, n. 1, p. 122-132, 2010.

SEVERINO, A. J. Metodologia do trabalho científico. 23ํe ed. São Paulo, Cortez, 2007.

SILVA, M. N. A Educação Ambiental na sociedade atual e sua abordagem no ambiente escolar. Portal de e - governo, inclusão digital e sociedade do conhecimento, 2012.

Disponível em: $<$ http://www.egov.ufsc.br/portal/conteudo/educa\%C3\%A7\%C3\%A3o-ambientalna-sociedade-atual-e-sua-abordagem-no-ambiente-escolar>. Acesso: 22 jul. 2020.

SILVA, C. K. F.; CARNEIRO, C. Um breve histórico da Educação Ambiental e sua importância na escola. In: Congresso Nacional de Educação - CONEDU, 4., 2017, João Pessoa, PB. Congresso... João Pessoa: CEMEP e UEPB Universidade Estadual da Paraíba, 2017. Disponível em: <https://editorarealize.com.br/revistas/conedu/trabalhos/TRABALHO EV073 M D1 SA14 ID9579 12102017144004.pdf>. Acesso: 28 abr. 2020.

SOBRAL, M. M. A importância do pensamento reflexivo crítico e criativo na Educação Ambiental. Revista Brasileira de Educação Ambiental (Revbea), São Paulo, v. 9, n. 2, p. 314-343, dez. 2014.

SORRENTINO, M.; TRAJBER, R.; FERRARO JR., L. A. Educação Ambiental como Política Pública. Educação e Pesquisa, São Paulo, v. 31, n. 2, p. 285299, 2005.

SPRESTESOJO, L. A. C. D.; MAZARI, E. J.; GIROTTI, V. B. S. Práticas sobre consciência ambiental a partir da implantação de horta na educação infantil. Trilhas Pedagógicas, v. 7, n. 7, p. 329-350, Ago. 2017.

TIRIBA, L. Crianças da natureza: Educação Ambiental para Sociedades Sustentáveis. In: SEMINÁRIO NACIONAL: CURRÍCULO EM MOVIMENTO, 1., 2010. Anais... Belo Horizonte: Núcleo Interdisciplinar de Meio Ambiente/NIMA, PUC-RIO, 2010. $\quad$ p. 1-20. Disponível em: $<$ http://portal.mec.gov.br/docman/dezembro-2010-pdf/7161-2-9-artigo-meccriancas-natureza-lea-tiriba/file>. Acesso: 22 jul. 2020.

TOZONI-REIS, M. F. C. et al. A inserção da Educação Ambiental na educação básica: que fontes de informação os professores utilizam para sua formação? Ciência \& Educação, Bauru, v. 19, n. 2, p. 359-377, 2013. 